\title{
Determinants of Relationship Quality: A Cross-Cultural Study
}

\author{
Tadinac $\mathrm{M}$. \\ University of Zagreb, Zagreb, \\ Croatia
}

\author{
Bajoghli H., Joshaghani N. \\ Tehran University of Medical \\ Sciences, Tehran, Iran
}

\author{
Hromatko I., Jelić M., \\ Kamenov Ž. \\ University of Zagreb, Zagreb, Croatia
}

\begin{abstract}
It has been suggested that the cross-cultural universality of pair-bonding reflects its adaptive function. Along with this line of reasoning, we hypothesised that partners' perceptions of the relationship quality should also be determined by a cross-culturally universal mechanism of cost-benefit analysis. Therefore, the aim of this study was to compare the predictors of relationship quality in two different cultures and explore whose features of a relationship might be considered as universal predictors of its quality. Ninety nine Iranian married and 99 Croatian married or cohabiting couples were included in a dyadic assessment. The highest between-culture similarities were found for the "frequency of positive interactions" and the "profit in mate value" (difference in own and partner's perceived mate value). Sexual satisfaction proved to be a significant predictor only in the Croatian sample, while the number of children predicted the relationship quality in Iranian couples only. Other variables, such as difference in partners' age, income and education showed a more complex culture- and gender-dependent pattern. The results are in accordance with the notion that while the cost-benefit analysis itself is a universal process, the perception of certain costs and benefits is culturally specific.
\end{abstract}

Keywords: relationship quality, positive interactions, mate value, sex differences, cross-cultural comparison

\section{Introduction}

Partners' perception of marital/relationship quality heavily depends upon societal norms and expectations that partners draw from internalised cultural standards (Berscheid, 1995; Fiske, Kitayama, Markus, \& Nisbett, 1998). However, evolutionary theory posits that the cross-cultural universality of pair-bonding and marital alliances suggests that there is an adaptive function to it (Shackelford \& Buss, 1997; R. J. Quinlan \& M. B. Quinlan, 2007; Lucas et al., 2008). Romantic feelings, attachment towards the partner and relationship satisfaction in general might be seen as psychological adaptations which maintain the relationship, thus increasing the likelihood of children's survival and well-being. Huge amount of research has shown a cross-cultural universality of sex differences in mate preferences, with women seeking men of higher social and financial status, somewhat older, mature and emotionally stable, and men seeking young, healthy, attractive and reproductively capable women (Kenrick, Sadalla, Groth, \& Trost, 1990; Feingold, 1992; Buss \& Schmitt, 1993;

Tadinac M., Ph.D., psychologist, Department of Psychology, Faculty of Humanities and Social Sciences, University of Zagreb. Bajoghli H., MD, psychiatrist, Psychiatry and Psychology Research Center, Roozbeh Hospital, Tehran University of Medical Sciences.

Joshaghani N., MD, psychiatrist, Psychiatry and Psychology Research Center, Roozbeh Hospital, Tehran University of Medical Sciences.

Hromatko I., Ph.D., psychologist, Department of Psychology, Faculty of Humanities and Social Sciences, University of Zagreb. Jelić M., Ph.D., psychologist, Department of Psychology, Faculty of Humanities and Social Sciences, University of Zagreb. Kamenov Ž., Ph.D., psychologist, Department of Psychology, Faculty of Humanities and Social Sciences, University of Zagreb. 
Waynforth \& Dunbar, 1995; Buss, 1999). However, the importance of certain characteristics (such as chastity and high education) varies across cultures (Buss et al., 1990), as well as across genders. From an evolutionary psychological perspective, the perception of relationship quality can be regarded as a psychological device gauging the overall costs and benefits of a marriage (Shackelford \& Buss, 1997). Moreover, according to the social exchange theory, relationships will continue only, if both partners feel that they are coming out of the exchange with more than they had to give-up, that is, if they perceive a positive amount of profit (Levinger, 1976). This kind of cost-benefit analysis should be a universal process, while the perceived costs and benefits could be culturally specific, meaning that one might expect the existence and size of sex differences in perception of relationship/marriage quality to differ across cultures.

Several groups of variables have been frequently investigated as potential predictors of quality and/or stability of relationship: "socio-demographic variables", such as sex and age of the partner (Karney \& Bradbury, 1995; Heaton \& Blake, 1999), various measures of socio-economic status, including: income (Koehne, 2000; Zeng, 2000); employment (Corley \& Woods, 1991; Cudina-Obradovic \& Obradovic, 2006); education (Cudina-Obradovic \& Obradovic, 2006; Koehne, 2000); religion (Heaton, 2002); "certain aspects of the relationship", such as the duration of the relationship and/or previous cohabitation (Heaton, 2002; Brown, 2004) and children (Singh \& Willaims, 1981); "attachment styles of both partners" (Bartholomew \& Horowitz, 1991; Brennan, Clark, \& Shaver, 1998; Fraley \& Shaver, 2000); "sexual aspects of the relationship" (Byers \& Heinlein, 1989; S. S. Hendrick \& C. Hendrick, 1995; Gossman, Mathieu, Julien, \& Chartrand, 2003); "communication and interaction between partners" (Carstensen, Gottman, \& Levenson, 1995; Stanley, Markam, \& Whitton, 2002; Driver \& Gottman, 2004); "perception of investments" by partners (van Yperen \& Buunk; 1990; Brehm, 1992; Kamenov, Jelić, Tadinac, \& Hromatko, 2007); and partners' "mate value" (value on the "mating market"; Symons, 1979; Shackelford \& Buss, 1997; Shackelford, 1998; Buss, 2003; Buston \& Emlen, 2003). Although some of the investigated variables, such as positive interactions between partners, proved to be quite unambiguously positively correlated with the satisfaction in a relationship, others - mostly demographic variables and those pertaining to duration of the relationship — showed a more complex pattern of results.

Therefore, in this study, we used a set of demographic data (age, education, income and employment), some characteristics of the relationship (duration of dating before marriage/cohabitation, duration of marriage/cohabitation and number of children), frequency of positive interactions between partners, sexual satisfaction and perception of own and partner's mate value as predictors of the relationship quality. The data were collected on both partners within the couple, thus enabling us to use a within-couple discrepancy in certain variables as predictors of relationship quality. Furthermore, we compared these predictors in two very dissimilar cultures: Iran and Croatia. These two cultures differ on various levels of comparison: in dominant religion (Islam/Catholicism), politically (theocratic republic/parliamentary democratic republic) and geographically (south-west Asia/south-east Europe). In Iran, marriage is viewed as the sole socially approved pathway to sexual access and sex before marriage is still a rare exception (Hojat et al., 2000). In Croatia, on the other side, sex before marriage is practically a norm and although cohabitation was traditionally viewed as a step leading to marriage, nowadays, it is being recognized as an alternative form of marriage (Cudina-Obradovic \& Obradovic, 2006).

We hypothesised that certain aspects of a relationship will explain similar proportions of variance in relationship quality across cultures and genders (those reflecting previously mentioned universal processes of 
cost-benefit analysis), while the predictive power of others (especially the ones that previously gave inconsistent results, such as various demographic variables) will prove to be more culture and/or gender specific.

\section{Method}

\section{Participants and Procedure}

A total of 99 Iranian married couples and 99 Croatian married or cohabiting couples were included in a dyadic assessment (77 of 99 Croatian couples were married, and did not differ from the 22 cohabiting couples in any relevant variable, such as age, duration of relationship and cohabitation, quality of relationship, etc.). It was a convenience sample, recruited by using a "snowball" method. The researcher (one of the authors or a resident student) was present, while both partners filled out the questionnaires, thus, ensuring their independent responding to the questions. The envelopes were then sealed and returned to the principal investigators.

A prerequisite for participation in the study was that the couples were married or cohabiting for a period of minimum 12 months $\left(M_{\text {Iran }}=90, S D=89 ; M_{\text {Croatia }}=94, S D=83 ; F=0.14\right.$, n.s. $)$, thus, ensuring they had enough experience concerning the relevant dyadic assessment variables. The average age difference between partners was slightly higher in Iranian $(M=3.6, S D=2.9)$ compared to Croatian $(M=2.8, S D=3.1)$ couples. However, this difference did not reach statistical significance $(F=3.32$, n.s.). Iranian couples had a significantly $(F=45.85, p<0.001)$ shorter period of dating before marriage $(M=16.5, S D=17.7$ months $)$ than Croatian couples $(M=40.0, S D=29.6$ months). Iranian men did not differ from Croatian men in either age $(F=0.34$, n.s. $)$ or type of employment $\left(\chi^{2}=5.5\right.$, n.s. $)$, but there were differences in educational level $\left(\chi^{2}\right.$ $=47.07, p<0.01$ ), with a higher proportion of participants with a Ph.D., or masters degree in the Iranian sample. Iranian women did not differ from Croatian women in age $(F=0.39$, n.s. $)$, but again, there was a difference in educational level $\left(\chi^{2}=14.73, p<0.01\right)$, with a higher proportion of university level educated participants in Iranian sample. The type of employment also differed among women in two samples $\left(\chi^{2}=\right.$ $42.39, p<0.01$ ), with higher proportion of housewives in Iranian sample. These characteristics of samples are shown in Table 1. The number of children per couple did not differ between samples $\left(M_{\text {Iran }}=1.04, S D=\right.$ $1.2 ; M_{\text {Croatia }}=1.00, S D=0.89 ; F=0.07$, n.s.).

Table 1

Demographic Characteristics of the Sample

\begin{tabular}{|c|c|c|c|c|c|}
\hline & & \multicolumn{2}{|c|}{ Iran } & \multicolumn{2}{|c|}{ Croatia } \\
\hline & & Men & Women & Men & Women \\
\hline \multicolumn{2}{|l|}{ Age $(M \pm S D)$} & $34.9(7.2)$ & $31.3(6.7)$ & $34.7(7.3)$ & $31.9(6.7)$ \\
\hline \multirow{4}{*}{ Education (\%) } & Elementary school or lower & 3 & 4 & 4 & 3 \\
\hline & High school or vocational school & 17.1 & 28.3 & 60.6 & 54.5 \\
\hline & University & 54.5 & 48.5 & 32.3 & 33.3 \\
\hline & Master or Ph.D. & 25.3 & 19.2 & 3 & 9.1 \\
\hline \multirow{4}{*}{ Employment (\%) } & Employed or self-employed & 95.9 & 56.5 & 85.9 & 78.6 \\
\hline & Unemployed & 0 & 0 & 3.2 & 9.1 \\
\hline & Housekeeper & 0 & 37.4 & 0 & 3.0 \\
\hline & Retired (other) & $2(2)$ & $1(5.1)$ & $6.1(1)$ & $0(6.1)$ \\
\hline
\end{tabular}

Note. Due to a small proportion of missing values, the percentages do not always add up to $100 \%$. 


\section{Instruments}

"Demographic information form" was used to collect the relevant information on age, education, income, employment, duration of dating before marriage/cohabitation, duration of marriage/cohabitation and number of children.

"The MVI (mate value inventory)-7" (Kirsner, Figueredo, \& Jacobs, 2003) consists of 17 items - attributes considered to be important aspects of one's mate value (such as attractive face, attractive body, healthy, intelligent, faithful, etc.). Participants were instructed to rate themselves on each of 17 attributes, in a scale from -3 (extremely low on this trait) to +3 (extremely high on this trait), and then to rate their partner on the same scale. The result was then transformed into 1-7 scales, and the total score was the average value obtained on all the items. Internal consistencies of self-estimates in the male and female subsamples were $\alpha=0.83$ and $\alpha$ $=0.85$ for Croatian sample, and $\alpha=0.87$ for both Iranian subsamples. The internal consistencies of the estimates of partners for men and women were $\alpha=0.87$ and $\alpha=0.89$ in Croatian sample, and $\alpha=0.90$ and $\alpha=$ 0.88 in Iranian sample. From the original assessments of each partner, we computed a new measure, named "profit in the mate value", as the difference between partner's and own mate value. Theoretical total range of this variable is between -6 and +6 .

"DAS (Dyadic Adjustment Scale)-7" (Spanier, 1976) is a self-report instrument that measures various aspects of marital function, with higher scores indicating better adjustment. For the purpose of this research, we used only the part of the instrument assessing the frequency of positive interactions between partners (items, such as "How often do you laugh together?"), from 0 (Never) to 5 (More than once a day). The total score is a sum of answers on all the items, ranging form 0 to 25 . The reliability of the scale was $\alpha=0.77$ for men and $\alpha=$ 0.79 for women in Croatian sample, and $\alpha=0.68$ for men and $\alpha=0.77$ for women in Iranian sample.

"Index of Sexual Satisfaction" (Hudson, Fischer, \& Corcoran, 1994) was used to measure the subject's degree of sexual satisfaction. This scale consists of 25 statements regarding sexual aspects of the relationship, and the participants assess how often this can be applied to them (1 meaning "None of the time" and 7 meaning "All of the time"). The total score is formed according to the formula provided by the authors, ranging from 0 to 100 , the higher score meaning greater dissatisfaction, i.e., lesser satisfaction. The reliability of this scale was $\alpha=0.71$ for men and $\alpha=0.65$ for women in Iranian sample, and $\alpha=0.88$ for both men and women in Croatian sample.

The quality of the relationship was measured by the modified "Quality of marriage index" (Norton, 1983), comprising six items. On five of the items participants expressed their (dis)agreement in the 7-point scale $(1=$ "Completely disagree"; 7 = "Completely agree"; e.g., "We have a good relationship"), while on the sixth item they had to assess their happiness in the current relationship in a 10-point scale ( 1 = "very unhappy"; $10=$ "very happy"; "In general, how happy are you in the relationship with your partner?"). The total range of this measure is 6 to 45, with higher values meaning higher relationship quality. The Cronbach alpha coefficients for Iranian men and women were $\alpha=0.94$ and $\alpha=0.93$, respectively, and for Croatian men and women $\alpha=0.96$ and $\alpha=0.97$, respectively.

\section{Results}

\section{Culture and Sex Differences in Criterion and Predictor Variables}

As it can be seen from Table 2, compared to their Iranian counterparts, both Croatian men $(F=37.58, p<$ $0.001)$ and Croatian women $(F=11.31, p<0.001)$ perceive their relationship to be of a greater quality. 
Interestingly, while there were no sex differences in Iranian sample $(t=0.55$, n.s.), Croatian men assess their relationship to be of a slightly greater quality than their partners do $(t=3.43, p<0.001)$. Furthermore, the correlations between partners' assessments of the relationship quality are moderate in size for both Iranian ( $r=$ $0.60, p<0.001)$ and Croatian $(r=0.65, p<0.001)$ couples. Therefore, the regression analyses were done for each sex, separately.

Table 2

Quality of a Relationship, Frequency of Positive Interactions, Sexual Satisfaction and Profit in Mate Value in Iranians and Croatians

\begin{tabular}{|c|c|c|c|c|}
\hline & \multicolumn{2}{|c|}{$\begin{array}{c}\text { Iran } \\
(n=99 \text { couples })\end{array}$} & \multicolumn{2}{|c|}{$\begin{array}{c}\text { Croatia } \\
(n=99 \text { couples })\end{array}$} \\
\hline & Men & Women & Men & Women \\
\hline Quality of relationship & $34.6(7.8)$ & $35.0(7.7)$ & $40.8(6.3)$ & $38.7(7.8)$ \\
\hline Frequency of positive interactions & $3.4(0.8)$ & $3.4(0.8)$ & $3.7(0.8)$ & $3.7(0.6)$ \\
\hline Sexual satisfaction & $46.5(8.8)$ & $47.9(8.3)$ & $22.1(14.1)$ & $23.4(14.2)$ \\
\hline Profit in mate value & $0.1(0.7)$ & $0.3(0.6)$ & $0.3(0.4)$ & $0.2(0.7)$ \\
\hline
\end{tabular}

Note. Standard deviations are in brackets.

Descriptive statistics for demographic variables (age, education and employment) and those relating to some aspects of the relationship (duration, the number of children) have already been presented in the section "participants". Here, we present the cultural and sex differences in the remaining predictor variables: the frequency of positive interactions, sexual satisfaction and "profit" in mate value. The means and standard deviations for those variables are also shown in Table 2. ANOVA showed significant main effects of culture for the "frequency of positive interactions" $\left(F_{\mathrm{men}}=4.9, p<0.03 ; F_{\text {women }}=7.2, p<0.001\right)$, "sexual satisfaction" $\left(F_{\text {men }}=213.8, p<0.001 ; F_{\text {women }}=219.4, p<0.001\right)$ and "profit in mate value" for men $(F=8.1, p<0.01)$, but not for women $\left(F_{\text {women }}=0.1\right.$, n.s.). Comparison of partners within the couple showed that partners assessed the "frequency of positive interactions" equally $\left(t_{\text {Croatia }}=0.29 ; t_{\text {Iran }}=0.13\right.$, both n.s.). There was no within-couple sex difference in the perception of "mate value profit" in the Croatian sample $(t=1.1$; n.s.), and a marginally significant difference in Iranian sample $(t=1.9, p=0.054$.), with women perceiving a larger profit. The partners in the Croatian sample were equally satisfied with sexual aspects of their relationship $(t=0.9$, n.s.), while women in the Iranian sample were somewhat more sexually dissatisfied than their partners $(t=2.1, p<0.05)$.

\section{Predictors of Relationship Quality in Two Cultures}

In order to answer the research problems, we have conducted several regression analyses, for each sex and country independently. As it can be seen from Table 3, the chosen predictors explained similar proportions of variance in all four subsamples, but the significant predictors varied among the subsamples and shall be discussed further in the discussion.

\section{Discussion}

Croatian women, and especially men, assessed the quality of their relationship to be higher than Iranian men and women did. Furthermore, we also found significant main effects of culture for the "frequency of positive interactions" and "sexual satisfaction", while for the "profit in mate value" the effect of culture was significant for men, but not for women. These results show that Iranian couples have fewer positive interactions, greater sexual dissatisfaction and that Iranian men perceived smaller profit in mate value in comparison to 
Croatian men. All these differences, being significant predictors of relationship quality (as it shall be discussed in the following sections of this text), can probably explain the cultural difference in the quality of relationship as well.

Table 3

Results of Regression Analyses With Quality of Relationship as Criterion Variable

\begin{tabular}{lcccc}
\hline & \multicolumn{2}{c}{ Iran } & \multicolumn{2}{c}{ Croatia } \\
\cline { 2 - 5 } \cline { 4 - 5 } Predictors & Men & Women & \multicolumn{2}{c}{ Momen } \\
\hline Age difference & \multicolumn{1}{c}{$\beta$} & $0.19^{*}$ & -0.14 & 0.03 \\
Difference in educational level & $-0.34^{* *}$ & -0.01 & 0.10 & 0.08 \\
Difference in income & $0.23^{*}$ & -0.11 & $0.20^{*}$ & -0.15 \\
Duration of dating & 0.01 & $-0.48^{* *}$ & 0.03 & -0.03 \\
Duration of marriage & 0.24 & 0.10 & -0.20 & -0.17 \\
Number of children & $-0.39^{*}$ & $-0.30^{*}$ & 0.06 & 0.17 \\
Frequency of positive interactions & $0.45^{* *}$ & $0.48^{* *}$ & $0.39^{* *}$ & $0.21^{*}$ \\
Sexual satisfaction & 0.01 & 0.04 & $-0.28^{*}$ & $-0.26^{*}$ \\
Profit in mate value & 0.01 & $0.22^{*}$ & $0.32^{* *}$ & $0.45^{* *}$ \\
$R$ & $0.63^{* *}$ & $0.71^{* *}$ & $0.73^{* *}$ & $0.65^{* *}$ \\
\hline
\end{tabular}

Notes. ${ }^{* *} p<0.01 ;{ }^{*} p<0.01$. Criterion variable: Quality of relationship.

Comparison of partners within the couple showed that Iranian men and women gave very similar assessments of marriage quality, while Croatian men perceived the quality of their relationship as higher in comparison to Croatian women. There were no within-couple sex differences in the "frequency of positive interactions". The difference in perception of "profit in mate value" was not significant in Croatian sample, and marginally significant in Iranian sample, where men perceived their profit to be smaller in comparison to the profit perceived by their spouses. Furthermore, the partners in the Croatian sample were equally satisfied with sex, while women in the Iranian sample were somewhat more sexually dissatisfied than their partners.

The main goal of our study was to identify the predictors of relationship quality in the Iranian and Croatian couples. As it can be seen from Table 3, the only predictor that proved to be significant in both men and women of both countries was the "frequency of positive interactions". This finding is in line with the behavioural theory of marriage, as well as with the social exchange theory, which posit that some behaviours (e.g., compliments and declarations of love) are perceived by the partner as rewards, while some others (e.g., critique or complaints) are perceived as punishments or losses. Rewarding behaviours enhance the evaluations of marriage quality, while punishing behaviours lower them (Willis, Weiss, \& Patterson, 1974; Markman, 1981; Bradbury \& Fincham, 1991). As the frequency of positive interactions were operationalized as the frequency of pleasant shared activities (such as kissing or laughing together), our findings are in accordance with those of A. K. Guilledge, M. H. Guilledge, and Stahmann (2003), who found that physical expressions of affection are highly correlated with relationship satisfaction, as well as with those of Carstensen et al. (1995), in whose study humour was shown to be one of the important features of happy marriages. The cross-cultural corresponding of the predictive value of positive interactions has already been shown in the study by Lucas et al. (2008), who found that their "love and partnership" scales were invariant across couples from four cultures (Britain, Turkey, China and US). This supports the notion that those scales measure an adaptively evolved component of marital satisfaction. If we compare the items in their scale with the ones comprised in the DAS scale that we used, it 
becomes obvious that they measure similar concepts (e.g., "Do you enjoy doing things together" compared to "How often you work together", or "Does you marriage have a romantic side" compared to "How often do you kiss", etc.). The pleasant shared activities represent positive reinforcement for both partners, thus enhancing their perception of the relationship quality. However, the relation between positive interactions and marriage quality is probably bidirectional: The partners who perceive their relationship as successful will also strive to spend more time together.

The other variable with a strong predictive power across cultures and genders was the measure derived from the MVI-the "profit in mate value", i.e., the difference between the perceived partner's and own mate value. It explained significant proportions of relationship quality in Croatian men and women, as well as in Iranian women. However, it was not predictive for the relationship quality of Iranian men. In our earlier study (Tadinac, Kamenov, Hromatko, \& Jelić, 2006), it was established that in happy couples, both men and women perceived their partner to have higher mate value than themselves. In this study, within-couple comparisons showed that in both Iranian and Croatian couples, each partner perceived the other partner to be of somewhat higher mate value than himself/herself (i.e., the score on the variable "profit in the mate value" is higher than zero). However, this score was significantly different from the zero value for Croatian men $(t=7.2, p<0.001)$, Croatian women $(t=2.9, p<0.01)$ and Iranian women $(t=4.5, p<0.001)$, but not for Iranian men $(t=1.5$, n.s.). This might explain the lack of predictive power of this measure in the subsample of the Iranian men.

The concept of mate value stems from the evolutionary psychology (Buss, 1999; 2003) and it is based on the assumption that individuals possessing traits that make them desirable on the "mating market" will have a higher reproductive success. As fitness is defined, in a classic Darwinian sense, as the number of individual offspring reaches the reproductive age and reproduces themselves, high value on the mate market will be reserved for individuals showing indicators of high reproductive value. Evidence shows that individuals with a high market value also have higher expectations, i.e., find the market value of their partner is more important than those with a low market value (Buston \& Emlen, 2003; Tadinac \& Hromatko, 2007). Therefore, the person in a relationship who perceives that he/she has profited in this aspect, will surely be more satisfied that the one who perceives a loss, and will regard his/her relationship as of higher quality. This explanation is supported by the finding that the profit in mate value has been found to be a significant predictor of the relationship stability (Tadinac et al., 2006). It should be noted that these findings are somewhat different from those reported by Shackelford and Buss (1997), who found that mate value discrepancy, irrespective of its direction (i.e., which partner had higher mate value) predicted marital dissatisfaction in both partners. They argued that the partner with a lower mate value could feel anxious about loosing his/her partner, which might ultimately lead to marital dissatisfaction. However, their measure of mate value was based on the assessments of two interviewers, while we used each partner's self-assessment, as well as the assessment of his/her partner: thus, in our case, a so-called "positive illusion" (Taylor \& Brown, 1988) might have entered the equation. Obviously, if both partners perceive the other one as having a higher mate value, one (or both) of them must be wrong. Murray, Holmes, and Griffin (1996a; 1996b) have shown that positive illusion and idealization of partner have beneficial effects on satisfaction in romantic relationships. This raises an interesting question of self-deception as an adaptive psychological mechanism (Trivers, 2000). It has been shown previously that self-deception has a protective function in terms of psychological well-being (Paulhus \& Trapnell, 2008), and in this case, it could be postulated that a slight over-estimate in perception of partner's qualities might also serve as a proximal mechanism in maintaining the relationship satisfaction and stability. 
The age difference that emerged as a significant predictor for Iranian women might also be explained in terms of mate value: It has been shown cross-culturally (Buss et al., 1990) that older, more established men are valued higher as potential partners. Indeed, in our sample, there was also a moderate, but significant correlation between man's age and income: $r=0.35$. In men (both Croatian and Iranian), there was another significant predictor- "difference in income": The more they earn compared to their partners, the greater the quality of their relationship. Although this predictor did not reach statistical significance in women, there was a trend-as one might expect—in the opposite direction (The more he earns compared to her, the greater the relationship quality, in both countries). This might be explained as a remnant of a traditional patriarchal ideology still present in both countries - for example, in traditional Iranian culture, a husband is stigmatized, if he is not able to bring home more money than his wife (Hojat et al., 2000). These traditional views are represented in differences in gender roles acquired through the socialisation process. However, Croatian women nowadays have more egalitarian views than men (Office for Gender Equality of the Government of the Republic of Croatia, 2009), probably due to the fact that the majority of them are employed and providing for their families as well, which is probably the reason why this predictor did not reach statistical significance in women. Again, the man's potential to provide resources for his family can also be viewed, from the evolutionary psychological perspective, as a signal of fitness, or mate value. Thus, the more he is able to provide for his partner, the greater his value on the partner market and greater the chances that he would be in a gratifying relationship.

The difference in the educational level significantly predicted the relationship quality in Iranian men, with larger discrepancy predicting lower quality, in accordance with a well established phenomenon of homogamy, i.e., the preference for similarity in certain characteristics (Buss, 1985). There was no such effect in the Croatian sample. One of the possible explanations of this cross-cultural difference is the discrepancy between educational level and income in Croatia: While Croatian men have lower educational levels than their partners $(t=-2.1, p<$ $0.001)$, they earn more $(t=3.8, p<0.001)$. In Iranian sample, men have both higher education $(t=3.1, p<0.001)$ and higher incomes than their partners $(t=10.1, p<0.001)$. Furthermore, similar education is one of the mate preferences that have already shown a high degree of cross-cultural variation (Buss et al., 1990).

Sexual satisfaction contributed to the relationship quality only in Croatian men and women, while in the Iranian sample, it was not a significant predictor. This is indeed an interesting finding, as the sexual satisfaction was previously shown to be a very strong predictor of marital satisfaction and quality (Blumstein \& Schwartz, 1983; Byers \& Heinlein, 1989; Pan, 1993; Hassebrauck \& Fehr, 2002). The difference in the level of sexual satisfaction between Iranian and Croatian samples is another conspicuous finding: both men and women in the Iranian sample declared a degree of sexual dissatisfaction which was significantly higher and less variable than those in the Croatian sample. These findings concerning the cross-cultural difference in the importance of the sexual aspect of the relationship could probably be explained with greater sexual liberties in Croatia compared to Iran, where reproduction is viewed as the primary function of marriage (Hojat et al., 2000). Another explanation is that marriage in Iranian culture is viewed as a permanent commitment to lifelong companionship, bonding not only the married couples, but also their families (Shapurian \& Hojat, 1985). This finding is in line with the triangular theory of love (Sternberg, 1986): According to this theory, sexual consummation is a part of passion. So, it seems that for Iranian couples commitment is more important compared to intimacy and passion. However, this proposition needs further investigation.

The number of children predicted the relationship quality in Iranian, but not in Croatian men and women. The negative correlation between the number of children and marital satisfaction is common in this type of 
research: Children increase the stability of marriage (at least when they are relatively young), but decrease its quality, because they are often a source of stress and tension in marriage (Belsky, 1990; Waite \& Lillard, 1991), they change the communication patterns between partners (Hoffman \& Manis, 1978), so that the perceived marital quality is negatively affected by parenting stress for both spouses (Lavee, Sharlin, \& Katz, 1996). The lack of correlation between number of children and the quality of relationship in Croatian sample might be a consequence of a reduced variance in this variable: Compared to the Iranian sample, where the number of children per couple ranged from zero to six, the maximal number of children per couple in the Croatian sample was three (with only three couples having three children). Additionally, children's age might influence marital satisfaction more than their number, due to different demands that children of various ages put on their parents. To explore whether this had contributed to different predictive power of this variable in our samples, we compared the proportion of children of certain ages in those two samples. Among the couples with children, there was no differences between Iranian and Croatian couples in the number of children older than $19\left(\chi^{2}=\right.$ 7.04 , n.s. $)$, the number of children aged 13-18 $\left(\chi^{2}=6.5\right.$, n.s. $)$, or the number of children aged 5-12 $\left(\chi^{2}=1.16\right.$, n.s.). However, significantly more Iranian couples reported having children in the youngest age group (younger than five): $67.8 \%$ compared to $43.1 \%$ Croatian couples $\left(\chi^{2}=7.33, p<0.03\right)$.

Generally, our findings are partly in accordance with the results of the meta-analysis (Karney \& Bradbury, 1995) of 110 studies from the field of marriage quality, which showed that the positive behaviour of a partner was the most predictive variable for both spouses. The frequency of positive interactions and the profit in mate value showed the highest between-culture similarities. However, the second strong predictor of marriage quality from the meta-analysis - the sexual satisfaction - proved to be a significant predictor only in the Croatian, but not in the Iranian sample. The other obvious cross-cultural difference that emerged in our study concerns the sex differences in predictors of relationship quality in two samples. As it can be seen from Table 3 , the three strongest predictors of relationship quality for Croatian men and women are identical: profit in mate value, sexual satisfaction and frequency of positive interactions. There was only one predictor significant for men only (difference in income). On the other hand, in the Iranian sample, there were two predictors of relationship quality significant for both spouses - the frequency of positive interactions and the number of children. Differences in income and the educational level were significant predictors for men, while for women, the marriage quality was also predicted by the age difference, profit in mate value and the duration of dating. The duration of dating was negatively correlated with the relationship quality: The longer the dating before marriage, the lower the perceived marriage quality. This is an unexpected finding: Maybe, the Iranian couples who dated for a longer period of time before they got married were more liberal and entered a love marriage (however, we did not ask them directly). It is not culturally approved for traditional couples in an arranged marriage to date a long time before marriage. Furthermore, sometimes, in traditional, societies arranged marriages may work out the best (Gupta \& Singh, 1982).

Overall, within culture similarities of husbands and wives were much more pronounced in the Croatian sample than the Iranian one, in line with Lucas et al.'s (2008) observation that we often overlook the possibility that spousal discrepancies in marital satisfaction might also depend on culture. The lack of within culture similarities of husbands and wives in Iran might be due to the lack of equality between genders in Iranian couples. One can imagine that partners in a society with gender equality expect similar things from each other, but it might not be true in patriarchal societies. Iran is modernising and sex roles are changing to gender equality, but the remnants of patriarchy may still be more powerful in Iran compared to Croatia (Moghadam, 1992). 


\section{Limitations of the Presented Study}

Between-country differences notwithstanding, Table 2 shows that couples in both samples assessed the quality of their relationship/marriage relatively high. This stems from a methodological limitation of using a convenience sample, which probably led to a self-selection of participants. In other words, it is feasible to expect that unhappy couples, who are currently not on the best of terms, would not consent to take part in the study dealing with marriage quality. Therefore, unhappy couples are most likely missing from our samples. The generalizability of our results might be somewhat limited because of that, although the skewed distributions are not rare in this line of research (for a review, see Karney \& Bradbury, 1995). Furthermore, our samples were non-representative, consisting of predominantly urban and educated individuals. Apart from sample characteristics, another limitation stems from the use of instruments developed in a Western culture, which could have resulted in over-representation of concepts which are less important and omission of those who are relevant in non-Western cultures. However, the result of regression analyses show that the variables used in this study explain about equal share of relationship quality variance in both samples.

\section{Conclusions}

In conclusion, our results show that the perception of relationship quality depends on some concerns and preoccupations of spouses that could be viewed as adaptively universal, with the purpose of motivating the partners to hold on to their relationship, thus, ensuring better chances for a reproductive success. However, the criteria for assessment of relationship quality might be determined by culture and they can differ for husbands and wives within each culture.

\section{References}

Bartholomew, K., \& Horowitz, L. M. (1991). Attachment styles among young adults: A test of a four-category model. Journal of Personality and Social Psychology, 61, 226-244.

Belsky, J. (1990). Children and marriage. In F. D. Fincham, \& T. N. Bradbury (Eds.), The psychology of marriage: Basic issues and applications (pp. 172-200). New York: Guilford.

Berscheid, E. (1995). Help wanted: A grand theorist of interpersonal relationships, sociologist or anthoropologist preferred. Journal of Social and Personal Relationships, 12, 529-533.

Blumstein, P., \& Schwartz, P. (1983). American couples: Money, work, sex. New York: William Morrow and Company.

Bradbury, T. N., \& Fincham, F. D. (1991). A contextual model for advancing the study of marital interaction. In G. J. O. Fletcher, \& F. D. Funcham (Eds.), Cognition in close relationships. Hillsdale, N. J.: Erlbaum.

Brehm, S. S. (1992). Intimate relationships. New York: McGraw-Hill.

Brennan, K. A., Clark, C. L., \& Shaver, P. R. (1998). Self-report measures of adult romantic attachment: An integrative overview. In J. A. Simpson, \& W. S. Rholes (Eds.), Attachment theory and close relationships. New York: Guilford.

Brown, S. (2004). Moving from cohabitation to marriage: Effects on relationship quality. Social Science Research, 33, 1-19.

Buss, D., Abbot, M., Angleitner, A., Asherian, A., Biaggio, A., Blanco-Villasenor, A., ... Yang, K. (1990). International preferences in selecting mates: A study of 37 cultures. Journal of cross-cultural psychology, 21(1), 5-47.

Buss, D. M. (1985). Human mate selection. American Scientist, 73, 47-51.

Buss, D. M. (1999). Evolutionary psychology: The new science of the mind. Boston: Allyn \& Bacon.

Buss, D. M. (2003). The evolution of desire: Strategies of human mating. New York: Basic Books.

Buss, D. M., \& Schmitt, D. P. (1993). Sexual strategies theory: An evolutionary perspective on human mating. Psychological Review, 100, 204-232.

Buston, P. M., \& Emlen, S. T. (2003). Cognitive processes underlying human mate choice: The relationship between self-perception and mate preference in Western society. Proceedings of the National Academy of Sciences, 100, 8805-8810.

Byers, E. S., \& Heinlein, L. (1989). Predicting initiations and refusals of sexual activities in married and cohabiting couples. The Journal of Sex Research, 26, 210-231. 
Carstensen, L., Gottman, J., \& Levenson, R. (1995). Emotional behavior in long-term marriage. Psychology and Aging, 10, 140-149.

Corley, C. J., \& Woods, A. Y. (1991). Socioeconomic, sociodemographic and attitudinal correlates of the tempo of divorce. Journal of Divorce \& Remarriage, 16, 47-68.

Cudina-Obradovic, M., \& Obradovic, J. (2006). The psychology of marriage and family. Zagreb: Golden Marketing.

Driver, J. L., \& Gottman, J. M. (2004). Daily marital interactions and positive affect during marital conflict among newlywed couples. Family Process, 43(3), 301-314.

Feingold, A. (1992). Gender differences in mate selection preferences: A test of the parental investment model. Psychological Bulletin, 112, 125-139.

Fiske, A., Kitayama, S., Markus, H. R., \& Nisbett, R. E. (1998). The cultural matrix of social psychology. In D. Gilbert, S. Fiske, \& G. Lindzey (Eds.), The handbook of social psychology (4th ed., pp. 915-981). San Francisco: McGraw-Hill.

Fraley, R. C., \& Shaver, P. R. (2000). Adult romantic attachment: Theoretical developments, emerging controversies, and unanswered questions. Review of General Psychology, 4, 132-154.

Gossman, I., Mathieu, M., Julien, D., \& Chartrand, E. (2003). Determinants of sex initiation frequencies and sexual satisfaction in long-term couples' relationships. The Canadian Journal of Human Sexuality, 12(3-4), 169-181.

Guilledge, A. K., Guilledge, M. H., \& Stahmann, R. F. (2003). Romantic physical affection types and relationship stability. American Journal of Family Therapy, 31, 233-242.

Gupta, U., \& Singh, P. (1982). An exploratory study of love and liking and type of marriage. Indian Journal of Applied Psychology, 19, 92-97.

Hassebrauck, M., \& Fehr, B. (2002). Dimensions of relationship quality. Personal Relationships, 9, 253-270.

Heaton, T. B. (2002). Factors contributing to increasing marital stability in the United States. Journal of Family Issues, 23, 392-409.

Heaton, T. B., \& Blake, A. M. (1999). Gender differences in determinants of marital disruption. Journal of Family Issues, 20 , 25-45.

Hendrick, S. S., \& Hendrick, C. (1995). Gender differences and similarities in sex and love attitudes. Personal Relationships, 2 , 55-65.

Hoffman, L. W., \& Manis, J. D. (1978). Influences of children on marital interaction and parental satisfactions and dissatisfactions. In R. M. Lerner, \& G. B. Spanier (Eds.), Child influences on marital and family interaction (pp. 165-213). New York: Academic Press.

Hojat, M., Shapurian, R., Foroughi, D., Nayerahmadi, H., Farzaneh, M., Shafieyan, M., \& Parsi, M. (2000). Gender differences in traditional attutudes toward marriage and the family: An empirical study of Iranian immigrants in the United States. Journal of Family Issues, 21, 419-434.

Hudson, W. W., Fischer, J., \& Corcoran, K. (1994). Index of sexual satisfaction (ISS) (1980, 1982, 1992). In Measures for clinical practice: A sourcebook (pp. 190-191). New York: Free Press.

Kamenov, Ž., Jelić, M., Tadinac, M., \& Hromatko, I. (2007). Quality and stability of the relationship as a function of distribution of housework, financial investments, and decision making between partners. 15th Psychology Days in Zadar-Book of Selected Proceedings. Zadar: University of Zadar.

Karney, B., \& Bradbury, N. (1995). The longitudian course of marital quality and stability: A review of theory, method and research. Psychological Bulletin, 118, 3-34.

Kenrick, D. T., Sadalla, E. K., Groth, G., \& Trost, M. R. (1990). Evolution, traits, and stages of human courtship: Qualifying the parental investment model. Journal of Personality, 58, 97-116.

Kirsner, B. R., Figueredo, A. J., \& Jacobs, W. J. (2003). Self, friends, and lovers: Structural relations among Beck Depression Inventory scores and perceived mate values. Journal of Affective Disorders, 75, 131-148.

Koehne, K. (2000). The relationship between relational commitment, spousal intimacy, and religiosity and marital satisfaction. Dissertation Abstracts International, 61(6-B), 3322.

Lavee, Y., Sharlin, S., \& Katz, R. (1996). The effect of parenting stress on marital quality: An integrated mother-father model. Journal of Family Issues, 17, 114-135.

Levinger, G. (1976). A social psychological perspective on marital dissolution. Journal of Social Issues, 32, 21-47.

Lucas, T., Parkhill, M. R., Wendorf, C. A., Imamoglu, E. O., Weisfeld, C. C., Weisfeld, G. E., \& Shen, J. (2008). Cultural and evolutionary components of marital satisfaction: A multidimensional assessment of measurement invariance. Journal of Cross-Cultural Psychology, 39, 109-122.

Markman, H. J. (1981). Prediction of marital distress: A five year follow-up. Journal of Consulting and Clinical Psychology, 49, $760-762$. 
Moghadam, V. M. (1992). Patriarchy and the politics of gender in modernizing societies: Iran, Pakistan and Afghanistan. International Sociology, 7, 35-53.

Murray, S. L., Holmes, J. G., \& Griffin, D. W. (1996a). The benefits of positive illusions: Idealization and construction of satisfaction in close relationships. Journal of Personality and Social Psychology, 70, 79-98.

Murray, S. L., Holmes, J. G., \& Griffin, D. W. (1996b). The self-fullfilling nature of positive illusions in romantic relationships: Love is not blind, but prescient. Journal of Personality and Social Psychology, 71, 1155-1180.

Norton, R. (1983). Measuring marital quality: A critical look at the dependent variable. Journal of Marriage and the Family, 45, 141-151.

Office for Gender Equality of the Government of the Republic of Croatia. (2009). Perception, experiences and attitudes on gender discrimination in the Republic of Croatia. (Unpublished raw data).

Pan, S. (1993). A sex revolution in current China. Journal of Psychology \& Human Sexuality, 6, 1-14.

Paulhus, D. L., \& Trapnell, P. D. (2008). Self-presentation: An agency-communion framework. In O. P. John, R. W. Robins, \& L. A. Pervin (Eds.), Handbook of personality psychology. New York: Guilford.

Quinlan, R. J., \& Quinlan, M. B. (2007). Evolutionary ecology of human pair-bonds: Cross-cultural tests of alternative hypotheses. Cross-Cultural Research, 41, 149-169.

Shackelford, T. K. (1998). Divorce as a consequence of spousal infidelity. In V. C. de Munck (Ed.), Romantic love and sexual behaviors (pp. 135-153). Westport, C. T.: Praeger.

Shackelford, T. K., \& Buss, D. M. (1997). Marital satisfaction in evolutionary psychological perspective. In R. J. Sternberg, \& M. Hojjat (Eds.), Satisfaction in close relationships (pp. 7-24). New York: The Guilford Pres.

Shapurian, R., \& Hojat, M. (1985). Sexual and premarital attitudes of Iranian college students. Psychological Reports, 57, 67-74.

Singh, B. K., \& Williams, J. S. (1981). Childlessness and family satisfaction. Research on Aging, 3, 218-227.

Spanier, G. B. (1976). Measuring dyadic adjustment: New scales for assessing the quality of marriage and similar dyads. Journal of Marriage and the Family, 38, 15-28.

Stanley, S. M., Markman, H. J., \& Whitton, S. W. (2002). Communication, conflict, and commitment: Insights on the foundations of relationship success from a national survey. Family Process, 41, 659-675.

Sternberg, R. J. (1986). A triangular theory of love. Psychological Review, 93, 119-135.

Symons, D. (1979). The evolution of human sexuality. N. Y.: Oxford University Press.

Tadinac, M., Hromatko ${ }^{\odot}$, I. (2007). Own mate value and relative importance of a potential mate's qualities. Studia Psychologica, 49, 251-264.

Tadinac, M., Kamenov, Ž., Hromatko, I., \& Jelić, M. (2006). What makes an intimate relatioship succesful? Zagreb: FF Press.

Taylor, S. E., \& Brown, J. D. (1988). Illusion and well-being: A social psychological perspective on mental health. Psychological Bulletin, 103, 193-210.

Trivers, R. (2000). The elements of a scientific theory of self-deception. Annals of the New York Academy of Sciences, 907, 114-131.

van Yperen, N. W., \& Buunk, B. P. (1990). A longitudinal study of equity and satisfaction in intimate relationships. European Journal of Social Psychology, 20, 287-309.

Waite, L. J., \& Lillard, L. A. (1991). Children and marital disruption. American Journal of Sociology, 96, 930-953.

Waynforth, D., \& Dunbar, R. I. M. (1995). Conditional mate choice strategies in humans-evidence from lonely hearts advertisements. Behaviour, 132, 125-139.

Willis, T. A., Weiss, L. R., \& Patterson, G. R. (1974). A behavioral analysis of the determinants of marital satisfaction. Journal of Consulting and Clinical Psychology, 42, 802-811.

Zeng, W. (2000). Economic circumstances and the stability of nonmarital cohabitation. Journal of Family Issues, 21, 303-328. 